\title{
MICOTOXINAS DO FUSARIUM spp NA AVICULTURA COMERCIAL
}

\author{
MYCOTOXIN OF FUSARIUM spp IN COMMERCIAL POULTRY
}

\author{
Elizabeth Santin $^{1}$ Alex Maiorka ${ }^{2}$ Irineo Zanella ${ }^{3}$ Leandro Magon ${ }^{4}$
}

\section{- REVISÃO BIBLIOGRÁFICA -}

\section{RESUMO}

\begin{abstract}
Micotoxinas são metabólitos tóxicos produzidos por fungos, de natureza heterogênea e com variados princípios farmacológicos, que podem atuar sobre o organismo animal prejudicando o seu desempenho e desenvolvendo alterações patológicas graves. Nos últimos anos, as micotoxicoses têm recebido especial atenção devido às enormes perdas que vem causando na avicultura mundial. Fungos do gênero Fusarium são descritos como produtores de diversos tipos de toxinas. Assim sendo, as intoxicações causadas por essas micotoxinas, dificilmente ocorrerão devido a uma substância isolada, de forma que se faz necessário obter maiores informações sobre o efeito interativo dessas toxinas.
\end{abstract}

Palavras-chave: Fusarium, micotoxinas, aves.

\section{SUMMARY}

Mycotoxins are fungi toxic metabolites, heterogeneous in their nature and with varied pharmacological actions. They can cause injuries to animals, resulting in decreased performance and serious pathologic lesion. In the last years, the mycotoxicosis has received special attention worldwide due to losses in poultry industry. Fusarium fungi are reported as producers of diverse mycotoxin. Therefore, intoxication caused by Fusarium mycotoxins will hardly be due to one separate substance and more information is needed about the interaction effect of these.

Key words: Fusarium, mycotoxin, poultry.

\section{INTRODUÇÃOO}

Fungos do gênero Fusarium destacam-se como um dos mais importantes em termos de perdas globais devido às micotoxicoses (SMITH \&
SEDDON, 1998). Isso se deve ao fato desse gênero ter a capacidade de produzir uma variedade de micotoxinas, sendo as mais importantes os tricotecenos (vomitoxina e T-2 entre outras), as fumonisinas, a zearalenona, a moniliformina e o ácido fusárico.

Os cereais que constituem a dieta das aves, certamente, são a principal fonte dessas toxinas para os animais, uma vez que servem de substrato para o crescimento dos fungos e a consequiente produção de micotoxinas. Porém, nem todo o cereal infestado por fungos está necessariamente contaminado por micotoxinas, uma vez que a produção e concentração dessas substâncias é determinada por efeitos combinados das espécies de fungos presentes, temperatura e da umidade do grão (RAMAKRISHNA et al., 1996). Quando as micotoxinas estão presentes na dieta, vários fatores associados à espécie animal, concentração e natureza da toxina vão determinar o efeito no organismo exposto a essas substâncias.

No Brasil, existem poucos relatos sobre a incidência de fusariotoxinas, entretanto CASTRO et al. (1995) apresentam que a micoflora dos grãos de milho do estado de São Paulo constitui-se, predominantemente, de fungos do gênero Fusarium; tendo esse gênero incidência muito maior que o gênero Aspergillus; em adição, ORSI et al. (1995) demonstram que dentre o gênero Fusarium a espécie Fusarium moniliforme é a mais freqüente. Considerando essa população fúngica e que as fusariotoxinas são produzidas, na sua maioria, sob

\footnotetext{
${ }^{1}$ Médico Veterinário.

${ }^{2}$ Zootecnista.

${ }^{3}$ Zootecnista Professor do Departamento de Zootecnia da Universidade Federal de Santa Maria (UFSM), 97105-900, Santa Maria, RS.

E-mail: izanella @ccr.ufsm.br. Autor para correspondência.

${ }^{4}$ Acadêmico de Medicina Veterinária - UFSM.
} 
alta umidade e em temperaturas de aproximadamente 20 a $26^{\circ} \mathrm{C}$, o clima brasileiro oferece boas condições para que essas toxinas estejam presentes nos grãos utilizados nas dietas dos animais. Ademais, mesmo na ausência de literatura que comprove a ocorrência de fusariotoxicose no Brasil, muitos veterinários e técnicos de campo afirmam observarem lesões orais de necrose e descamação, principalmente em aves de postura, em ocasiões em que a qualidade do milho da dieta está abaixo do esperado.

Sendo assim, o presente artigo tem como objetivo fazer uma abordagem das informações disponíveis sobre fusariotoxicoses, suas alterações patológicas e implicações no desempenho zootécnico e econômico das aves domésticas. Apesar de cada toxina ser, aqui, tratada separadamente é importante destacar que dificilmente se encontra apenas uma delas atuando, isoladamente, na natureza.

\section{Tricotecenos}

Os tricotecenos (12,13-epoxytrichothecenos) são um grupo de mais de cem micotoxinas e possuem esse nome devido a sua estrutura química, composta de um anel com esqueleto tetracíclico 12,13-epoxitricotecenos. Essas toxinas são classificadas em tipo A, na qual se encontram as toxinas T2, HT-2, 15-monoacetoxiscirpenol (15-MAS) e diacetoxiscirpenol (DAS), e em tipo B, na qual está o deoxinilvalenol (DON ou vomitoxina).

Genericamente, essas substâncias são descritas como potentes irritantes da pele e agentes inflamatórios com rápida destruição das células em divisão (MIROCHA \& PATHRE, 1973). Nesse prisma, DOERR et al. (1981) observaram que os tricotecenos podem agir inibindo a iniciação da síntese protéica nos ribossomas de células eucarióticas. Essas células necessitam de uma elevada taxa de síntese de proteínas para que seu genoma seja replicado, fazendo com que o mecanismo primário de inibição da síntese protéica celular pelos tricotecenos também afete a síntese de DNA que ocorre nas fases de divisão celular (THOMPSON \& WANNEMACHER, 1990). Em adição, os tecidos mais susceptíveis a essas micotoxinas serão aqueles que possuem altas taxas de regeneração, como os do trato gastrointestinal, pele, sistema linfático, sistema imunológico e células sangüíneas.

As primeiras investigações de $\mathrm{T}-2$ em poedeiras revelaram o desenvolvimento de uma lesão na cavidade oral sem alterações significativas nos órgãos ou nas funções neurológicas das aves (Speers et al. 1972, apud LEESON et al. 1995). Com o passar do tempo, essa lesão oral foi considerada como sendo clássica e patognomônica em casos de intoxicação por T-2, e WYATT et al. (1972) conduziram um estudo para descrever o desenvolvimento desse quadro. Esses autores observaram que a severa inflamação na boca aparecia quatro a sete dias após a ingestão da toxina, e era conseqüência do contato da substância com a mucosa, posteriormente, progredindo para necrose e sendo invadida pela microbiota oral. Microscopicamente, foi demonstrado uma resposta inflamatória intensa com necrose localizada (infiltração granular), podendo ocorrer desprendimento de material fibrinoso com pequenas áreas circulares e grande quantidade de bactérias. A T-2 também tem sido implicada como causa de empenamento anormal em aves, no entanto, ainda não ficou esclarecido se isto se deve à menor síntese protéica ou se é um efeito direto dessa toxina sobre o tecido folicular (PARKHURST \& HAMILTON, 1992).

De um modo geral, os tricotecenos classificados no tipo A possuem uma $\mathrm{DL}_{50}$ menor que a DON, definida como a menos tóxica dentro deste grupo de micotoxinas. No entanto, fatores inerentes ao animal, como idade de exposição, é que determinam o nível de toxicidade da substância. Hoerr $\boldsymbol{e t}$ al. (1982), apud LEESON et al. (1995), indicam que $10 \mathrm{mg} / \mathrm{kg}$ de T-2 por 7 dias é letal para aves.

Os tricotecenos, principalmente a DON, parecem interferir no consumo alimentar dos animais. Durante muito tempo, esse fato esteve relacionado com a dificuldade de ingerir ocasionada pela lesão oral clássica, no entanto, recentemente se observou que essas substâncias agem sobre o transporte do triptofano na barreira hemato-encefálica, aumentando os níveis desse aminoácido no cérebro e fazendo com que a quantidade de serotonina cerebral, um neurotransmissor responsável pelo comportamento e o apetite, também se eleve (CAVAN $\boldsymbol{e t}$ al., 1988).

Perus são descritos como sendo mais sensíveis que galinhas a essas substâncias. KESHAVARZ (1993) cita que o crescimento de poedeiras não foi afetado pelo milho contaminado com 2-3ppm de DON, no entanto perus alimentados com essa dosagem de toxina apresentam baixo desempenho e alta incidência de discondroplasia tibial. RICHARD et al. (1978) verificaram que a intoxicação por T-2 em perus resulta numa atrofia do timo, e, a evolução histológica dessa lesão revela uma depleção de linfócitos, sem que seja observado nenhum efeito sobre o tamanho da bursa, baço ou formação de anticorpos. BERGSJO \& KALDHUSDAL (1994) determinaram que 3 a 4ppm de DON não foram capazes de afetar o desempenho e a qualidade da carcaça de frangos corte, o que levou esses autores a concluírem que esses animais são pouco susceptíveis a essa toxina. 


\section{Zearalenona}

A zearalenona é um ácido com propriedades estrogênicas e as conseqüências são percebidas, principalmente, em suínos através da observação de indução de estro e vulvovaginites. SPEERS et al. (1971) citam que 300ppm de zearalenona pura causam um aumento no ganho de peso, no peso da crista, no comprimento do ovário, na incidência de cistos com aumento no peso da bursa de Fabricius de galinhas jovens, no entanto, CHI et al. (1980) mostraram que essa micotoxina pode causar redução no ganho de peso e no consumo alimentar sem a ocorrência de lesões pós-mortem.

Várias espécies e subespécies de fungos do gênero Fusarium são responsáveis pela produção de zearalenona $(F$. roseum, F.tricinctum, $F$. roseum "Culmorum", F.roseum 'Equiseti", F.roseum “Gibbosum", F.roseum "Graminearum", $F$. sporotrichioides, F.oxysporum e $F$. moniliforme). Como a maioria dessas espécies também são produtoras de outras toxinas como DON e T-2, é muito difícil que apenas a zearalenona seja encontrada ocorrendo naturalmente na natureza, quando essas espécies estão contaminado os grãos (SMITH e HENDERSON, 1991).

LARBIER \& LECLERQ, 1992, citam que as aves são bastante toleráveis à zearalenona, níveis de 800ppm não afetam o crescimento de frangos de corte e perus. Entretanto, em pintinhos de linhagem de postura, esses níveis promovem o desenvolvimento ovariano precoce, enquanto que em poedeiras adultas, $800 \mathrm{ppm}$ de zearalenona na ração não alteram a postura, o peso de ovo e a fertilidade, e tampouco alteram a capacidade reprodutiva dos machos, apesar de, em ambos os sexos, ser observada uma queda nos níveis de colesterol com níveis de 50ppm de zearalenona na dieta.

Perus parecem ser mais sensíveis que as outras aves a zearalenona, isso pode ser explicado pelo fato de que in vivo os perus metabolizam $100 \%$ da zearalenona em $\alpha$-zearalenol, enquanto que galinhas tendem a produzir iguais quantidades de $\alpha$ e $\beta$ zearalenol. O $\alpha$-zearalenol é, aproximadamente, três vezes mais estrogênico que o $\beta$-zearalenol (SMITH \& HENDERSON, 1991).

Em síntese, pode-se sugerir que as aves são bastante resistentes à intoxicação por zearalenona, entretanto as diversas associações dessa fusariotoxina com outras micotoxinas podem resultar em graves perdas e por isso merecem maiores estudos.

\section{Fumonisina}

Fumonisinas são as micotoxinas mais recentemente descobertas, sendo produzidas por fungos da espécie Fusarium moniliforme, contudo, outras espécies de Fusarium têm sido descritas como pro- dutores dessas toxinas, incluindo $\boldsymbol{F}$. proliferatum, $\boldsymbol{F}$. nygamai, $F$. anthophilue, $F$. dlamini e f. napiformi, além, de fungos do gênero Alternaria (NELSON, 1992). Existem 6 diferentes fumonisinas $\left(A_{1}, A_{2}, B_{1}\right.$, $\mathrm{B}_{2}, \mathrm{~B}_{3}$ e $\mathrm{B}_{4}$ ) sendo que a forma molecular predominante, produzida pelo Fusarium moniliforme, é a fumonisina $B_{1}$ (NORRED, 1993). Pouco se conhece sobre a temperatura ótima para produção de fumonisina, contudo sabe-se que está em torno de $20-28^{\circ} \mathrm{C}$. Ao contrário da maioria das micotoxinas, as fumonisinas não são fluorescentes quando incididas por luz ultravioleta (HENRY e WYATT, 1993). Essas micotoxinas têm sido associadas à leucoencefalomalácia eqüina, edema pulmonar em suínos, e indução de câncer hepático em ratos.

Em frangos de corte, LEDOUX et al. (1992) demonstraram que a fumonisina $B_{1}$ pode causar diminuição no ganho de peso, aumento no tamanho do fígado, proventrículo e moela, causando atrofia cortical tímica, necrose hepática multifocal e hiperplasia biliar. BROWN et al. (1992) demonstraram que essa toxina pode causar atrofia de vilos e hiperplasia de células caliciformes no jejuno. QURESHI et al. (1992) citam que a fumonisina pode afetar o sistema imune das aves, resultando em aumento na suceptibilidade a infecções.

O mecanismo de ação das fumonisinas parece estar relacionado com a síntese de esfingolípidios, que são importantes para integridade e atividade fisiológica celular, sendo encontrados em grandes quantidades no cérebro e tecido nervoso. Estudos in vitro têm apresentado que a fumonisina $B_{1}$ e $B_{2}$ são potentes inibidoras da biossíntese de esfingolipídios de hepatócitos e células renais de ratos. Sendo que a Fumonisina $\mathrm{B}_{1}$ também parece ser tóxica para macrófagos de galinha (HENRY \& WYATT, 1993).

ESPADA et al. (1994) citam que, em frangos de corte, a intoxicação por fumonisina pode revelar aumento nas concentracões séricas de cálcio, colesterol e da enzima aspartato amino transferase. Apesar disso, HENRY \& WYATT (1994) descrevem que $80 \mathrm{ppm}$ de fumonisina $\mathrm{B}_{1}$ pura não afetam o desempenho de frangos de corte.

É importante ressaltar que a maioria dos ensaios realizados com o objetivo de estabelecer os efeitos tóxicos das fumonisinas foram realizados com Material de Cultura Total (MCT) de Fusarium moniliforme, e NORRED (1993) afirma que alguns Fusarium são capazes de sintetizar não somente fumonisina como também moniliformina, fusarina, ácido fusarico e outros metabólitos citotóxicos, que podem dificultar a interpretação de experimentos que utilizam MCT de Fusarium moniliforme. No entanto, ESPADA et al.,(1994) afirma mque dietas contendo tanto $10 \mathrm{mg} / \mathrm{kg}$ de fumonisina $\mathrm{B}_{1}$ pura, quanto 
fumonisina derivada de MCT de Fusarium moniliforme, induzem diminuição no ganho de peso, aumento no peso relativo do fígado e diminuição no peso relativo do baço. Também foram observados diarréia, diminuição dos níveis séricos de triglicerídeos, ácido úrico e da atividade da fosfatase alcalina, com aumento do colesterol sérico, e dos níveis das enzimas aspartato amino transferase, gama glutamil transferase, desidrogenase lática e creatinina quinase.

\section{Ácido Fusárico}

O ácido fusárico é, provavelmente, uma das micotoxinas mais distribuídas na natureza uma vez que ela é produzida pela maioria das espécies do gênero Fusarium, tanto que BACON et al. (1996) sugeriram que essa micotoxina seja utilizada como indicador da contaminação de Fusarium em grãos e alimentos.

Essa micotoxina parece interferir com o consumo de alimentos dos animais, agindo sobre a utilização do triptofano pelo cérebro, que é precursor da serotonina, um neurotransmissor envolvido na regulação do consumo alimentar em aves domésticas. Normalmente, o triptofano é carreado pela albumina no sangue, e somente a sua forma livre pode cruzar a barreira hemato-encefálica, o que ocorre de maneira equilibrada (MACARI et al., 1994). O mecanismo com que o ácido fusárico aumenta as concentrações de triptofano cerebral difere dos tricotecenos. Enquanto estes últimos aumentam as concentrações de aminoácidos livres, por inibir a síntese protéica, e dessa forma elevar a taxa de triptofano que podem passar livremente pela barreira hemato-encefálica, o ácido fusárico, por ser derivado do triptofano, compete pelo sítios ligadores da albumina, deixando uma grande quantidade desse aminoácido livre, aumentando sua concentração no cérebro e, conseqüentemente, a síntese de serotonina.

$\mathrm{O}$ ácido fusárico possui a capacidade de aumentar a toxicidade de outras micotoxinas (BACON et al., 1995), e como não poderia ser diferente, essa micotoxina dificilmente aparece isolada em grãos contaminados por Fusarium, o que faz com que aumente sua importância nas micotoxicoses, uma vez que essa condição amplifica a habilidade do ácido fumárico de interagir com outras toxinas como as fumonisinas e a moniliformina (BACON et al., 1996).

\section{Moniliformina}

Várias espécies de fungos do gênero Fusarium podem produzir esta micotoxina (NELSON, 1992), que foi descrita por NAGARAJ $\boldsymbol{e t}$ al. (1995) como uma potente cardiotoxina quando administrada por via intravenosa em aves. Em frangos de corte, a presença de 100ppm de moniliformina na dieta reduziu o ganho de peso, diminui o peso relativo da bursa de Fabricius e aumentou o peso relativo do coração, elevando as concentrações de creatinina e cálcio séricos, e a atividade da fosfatase alcalina e da alanina aminotransferase (KUBENA et al., 1997). A moniliformina foi estudada em aves por ALLEN et al. (1981) que descreveram que essa toxina, na concentração de $64 \mathrm{ppm}$ na dieta em períodos acima de três semanas, pode provocar piora no desempenho e mortalidade dos animais alimentados.

Essa toxina parece agir inibindo o metabolismo intermediário do ciclo do ácido tricarboxílico (ciclo de Krebs), dessa forma sendo diferente dos tricotecenos (SMITH \& SEEDON, 1998). Como as outras toxinas do Fusarium, esta também assume importância devido a sua interação com outras micotoxinas, podendo aumentar seu poder de depleção sobre os animais.

\section{Controle das Fusariotoxicoses}

A melhor forma de evitar a presença de micotoxinas nas dietas animais é prevenir a sua formação. Práticas que diminuam a presença de insetos nas plantações de grãos e a umidade durante a armazenagem das matérias primas e rações são de extrema importância para impedir as condições ótimas para o desenvolvimento fúngico $\mathrm{e}$ a conseqüiente produção de suas toxinas. No entanto, em muitas situações, devido a questões de ordem prática e econômica, não é possível atender a essas exigências, e se faz necessário o controle das toxinas já formadas. Têm-se realizados vários estudos com o intuito de conter as micotoxicoses, no entanto, poucas técnicas desenvolvidas podem ser aplicadas na escala industrial da produção de cereais e de criações de animais.

O calor é um método físico descrito por DUPUY et al. (1993) como sendo capaz de diminuir de 87 a $100 \%$ as concentrações de fumonisina $B_{1}$ em grãos de milho, no entanto a temperatura deve ser em torno de 150 a $220^{\circ} \mathrm{C}$, o que pode levar a perda nutricional dos alimentos. VOSS et al. (1996) descreveram que a simples lavagem dos grãos, usando água e solução de carbonato de sódio, pode reduzir as concentrações de DON, zearalenona e fumonisina no milho. Entretanto essas técnicas são de pouca aplicabilidade para grande quantidade de grão, como ocorre nas fábricas de rações das indústrias avícolas.

Uma das formas mais utilizadas para conter micotoxinas já formadas em alimentos é o uso de substâncias adsorventes. Vários minerais têm sido avaliados com esse intuito, provavelmente devido à facilidade com que são incorporados às rações sem a necessidade de qualquer equipamento especial. $\mathrm{O}$ principal mecanismo de adsorção desses materiais está 
relacionado com a troca de cargas entre o adsorvente e a micotoxina. Entretanto, como as estruturas das micotoxinas são diferentes, sua eficácia não é igual para todas elas. Compostos adsorventes não nutritivos como aluminiosilicato, que estão sendo extensivamente utilizados na avicultura industrial para conter aflatoxinas, não são efetivos contra fumonisinas, DON e T-2 (BROWN et al., 1992; RAMOS \& HERNANDES, 1997), além de que, por compatibilidade de cargas elétricas essas substâncias também podem ser capazes de adsorver outros componentes da dieta, tais como promotores de crescimento e coccidiostáticos, aumentando a susceptibilidade dos animais à micoplasmose e coccidiose (SHRYOCK et al., 1994)

SMITH \& SEDDON (1998) observaram que um possível tratamento para as fusariotoxicoses pode estar baseado no mecanismo bioquímico de ação dessas toxinas sobre o metabolismo do triptofano, e que outros aminoácidos como leucina, isoleucina poderiam, eventualmente, agir como neutralizadores desse processo. É possível que, futuramente, possa-se encontrar algum benefício nessa linha de pesquisa, mas atualmente mais estudos são necessários.

Embora a eficiência da amoniação seja controvérsia entre diversos pesquisadores, quando associada a altas temperaturas ou alta pressão (60psi), essa técnica parece diminuir as concentrações de fumonisina $B_{1}$ no milho. Outros tratamentos alcalinos como o peróxido de hidrogênio e o bicarbonato de sódio com ou sem hidróxido de cálcio são eficazes na destruição da fumonisina $\mathrm{B}_{1}$ no milho (SCOTT, 1998).

É importante caracterizar que nenhuma dessas práticas de controle da toxina já formada são eficazes o bastante para reduzir totalmente as perdas ocasionadas aos animais; assim, a implantação de quaisquer uma dessas metodologias deve ser cuidadosamente avaliada do ponto de vista econômico.

\section{CONCLUSÕES}

As toxinas produzidas pelo gênero Fusarium são variadas, assim como são distintos suas formas de agirem no organismo animal. Sendo todas produzidas pelo mesmo gênero, essas micotoxinas, dificilmente, aparecem isoladas em casos de intoxicações, o que faz com que seja necessário que se conheçam os sinergimos entre elas. Como é possível observar, ainda não se aproxima o momento de certeza no controle da fusariotoxicoses; é importante que pesquisas sejam realizadas, e que os produtores estejam atentos às perdas ocasionadas por esse problema. Fazse necessário, para tanto, que métodos simples e confiáveis de detecção dessas toxinas sejam acessíveis, para que se possa quantificá-las nas dietas dos animais, e melhor conhecer as reais perdas resultantez delas.

\section{REFERÊNCIAS BIBLIOGRÁFICAS}

ALLEN, N.K., BURMEISTER, H.R., WEAVER, G.A., et al. Toxicity of dietary and intravenously administered moniliformin to broiler chickens. Poultry Science, v.60, p.1415-1417, 1981.

BACON, C.W., PORTER, J.K., NORRED, W.P. Toxic interaction of fumonisin $\mathrm{B}_{1}$ and fusaric acid measured by injection into fertile chicken egg. Mycopathol., v.129, p.2935,1995 .

BACON, C.W., PORTER, J.K., NORRED, W.P., et al. Production of fusaric acid by Fusarium species. Appl And Environm Microbiol, v.62, p.4039-4043, 1996.

BERGSJO, B., KALDHUSDAL, M. No association found between the ascites syndrome in broilers and feeding of oats contaminated whith deoxynivalenol up to thirty-five days of age. Poultry Science, v.73, p.1758-1762, 1994.

BROWN, T.P., ROTTINGHAUSGE, G.L., WILLIAMS, M.E. Fumonisin mycotoxicosis in broilers: Performance and pathology. Avian Dis, v.36, p.450-454, 1992.

CAVAN, K.R., MACDONALD, E.J., SMITH, T.K. Potential for dietary amino acid precursors of neurotransmitters to overcome neurochemical changes in acute T-2 toxicosis in rats. J Nutr, v.118, p.901-907, 1988.

CASTRO, M.F.P.M., SOARES, L.M.V., FURLANI, R.P.Z Mycoflora, aflatoxigenic species and mycotoxins in freshly harvested corn (zea mays L.): A preliminary study. Rev Microbiol, v.26, p.289-295, 1995.

CHI, M.S., MIROCHA, C.J., KURTZ, H.J., et al. Effect of dietary zearalenone on growing broiler chicks. Poultry Science, v.59, p.531-536, 1980.

DOERR, J.A., HAMILTON, P.B., BURMEISTER, H.R. T-2 toxicosis and blood coagulation in young chickens. Toxicol and Appl Pharmacol, v.60, p.157-162, 1981.

DUPUY, J., LE BARS, P., BOUDRA, H., et al. Thermo stability of fumonisin $\mathrm{B}_{1}$, a mycotoxin fron Fusarium moniliforme, in corn. Appl Environ Microbiol, v.59, p.2864-2867, 1993.

ESPADA, Y., GOPEGUI, R.R., CUADRADAS, C., $\boldsymbol{e t}$ al. Fumonisin mycotoxicosis in broilers. Weights and serum chemistry modifications. Avian Dis, v.38, p.454-460, 1994.

HENRY, M.H., WYATT, R.D. A review of fumonisin production by Fusarium moniliforme and fumonisin toxicosis in animals. J Appl Poultry Res, v.2, p.188-192, 1993.

HENRY, M.H., WYATT, R.D. The toxicity of purified fumonisin B1 in broiler chicks. Poultry Science, v.73 (suppl 1), p.100 (abstr.), 1994.

KESHAVARZ, K. Corn contaminated with deoxynivalenol: effects on performance of poultry. J Appl Poultry Res, v.2, p.43-50, 1993.

KUBENA, L.F., HARVEY, R.B., BUCKLEY, C.A., $\boldsymbol{e} \boldsymbol{t} \boldsymbol{a l}$. Individual and combined effects of moniliformin present in Fusarium fujikuroi culture material and aflatoxin in broiler chicks. Poultry Science, v.76, p.265-270, 1997.

LARBIER, M., LECLERCQ, B. Nutrition and feeding of poultry, Loughborough : Nottingham University, 1992. 305p. 
LEDOUX, D.R., WEIBKING, T.S., ROTTINGHAUS, G.E., $\boldsymbol{e}$ t al. Effects of Fusarium moniliforme culture material containing known levels of fumonisin $B_{1}$ on turkey poults. Poultry Science, v.71 (Suppl. 1), p.162 (abstr.), 1992.

LEESON, S., DIAZ, G.J., SUMMERS, J.D. Poultry metabolic disorders and mycotoxins. Guelph : University Books, 1995. p.352.

MACARI, M., FURLAN, R.L., GONZALES, E. Fisiologia aviária aplicada a frangos de corte. Jaboticabal. FUNEP/UNESP, 1994. 296p.

MIROCHA,C.J., PATHRE, S. Identification of the toxic principle in a sample of poaefusarin. Appl Microbiol, v.26, p.719-724, 1973.

NAGARAJ, R.Y., WU, W., WILL, J.A., et al. Cardiotoxicity of moniliformin in broiler chickens as measured by electrocaridiography. Poultry Science, v.74 (suppl1), p.21 (abstr.), 1995.

NELSON, P.E. Taxonomy and biology of Fusariun moliniform Mycopathologia, v.117, p.26-36, 1992.

NORRED, W.P. Fumonisins - mycotoxins produced by Fusariun moliniforme. J Toxicol Environ Health, v.38, p.309-328, 1993.

ORSI, R.P.B., CORREA, B., POZZI, C.R., et al. Microbiota fúngica em três híbridos de milho recém-colhidos e armazenados. In: SEMINÁRIO SOBRE A CULTURA DO MILHO "SAFRINHA", 3, 1995, Assis, SP. Anais... Assis : n.i., 1995. v.3. 32p.

PARKHURST, C.R., HAMILTON, T.B. Abnormal feathering of chicks caused by scirpenol mycotoxins differing in degree of acetylation. Poultry Science, v.71, p.833-837, 1992.

QURESHI, M.A, HANGLER Jr, W.M. Effect of fumonisin $B_{1}$ on chicken macrophage functions in vitro. Poultry Science, v.71, p.104-102, 1992.

RAMOS, A.J., HERNANDEZ, E. Prevention of aflatoxicosis in farm animals by means of hydrated sodium calcium aluminosilicate addition to feedstuffs: a review. Anim Feed Sci Technol, v.65, p.197-206, 1997.
RAMAKRISHNA, N., LACEY, J., SMITH, J.E. Aspergillus flavus colonization and aflatoxin $\mathrm{B}_{1}$ formation in barley grain during interactions with other fungi. Mycopathologia, v.136, p.53-63, 1996.

RICHARD, J.L., CYSEWSKI, S.J., PIER, A.C., et al. Comparison of effects of dietary T-2 toxin on growth, immunogenic organs, antibody formation, and pathologic changes in turkeys and chickens. Am J Vet Res, v.39, p.1674-1678, 1978.

SCOTT, P.M. Industrial and farm detoxification processes for mycotoxins. Revue Medicine Veterinaire, v.149:6, p.543-548, 1998.

SHRYOCK, T.R., KLINK, P.R., READNOUR, R.S., et al. Effect of bentonite incorporated in a feed ration with tilmicosin in the prevention of induced Mycoplasma gallisepticum airsacculitis in broiler chickens. Avian Diseases, v.38, p.501-505, 1994.

SMITH, J.E., HENDERSON, R.S. Mycotoxins and animal foods, Athens : CRC,1991. 108p.

SMITH, T.K., SEDDON, I.R. Synergism demonstrated between Fusarium mycotoxins. Feedstuffs, 22 de junho1998, p.12-17, 1998.

SPEERS, G.M., MERONUCK, R.A., BARNES, D.M., et al. Effect of feeding Fusarium roseum F.Sp Graminearum contaminated corn and the mycotoxin F-2 on the groing chick and layng hen. Poultry Science, v.50, p.627-630, 1971.

THOMPSON, W.L., WANNEMACHER, R.W. Jr. In vivo effects of T-2 mycotoxin on synthesis of proteins and DNA in rat tissues. Toxicol Appl Pharmacol, v.105 n.3, p.483-491, 1990.

VOSS, K.A., BACON, C.W., MEREDITH, F.I., et al. Comparative subchronic toxicity studies of nixtamalized and water-extracted Fusarium moniliforme culture material. Food Chem Toxicol v.34, p.623-632, 1996.

WYATT, R.D., WEEKS, B.A., HAMILTON, P.B., et al. Severe oral lesions in chickens caused by ingestion of dietary fusariotoxin T-2. Appl Microbiol, v.24, p.251-257, 1972.

Ciência Rural, v. 31, n. 1, 2001. 